\title{
Com educação a distância se vai ao longe*
}

Não é de hoje que a educação a distância (EAD) possibilita a inclusão daqueles que jamais poderiam estudar. $\mathrm{Na}$ época do Apartheid, a EAD propiciou que negros se graduassem sem freqüentar as aulas nas universidades, entre os quais, Nelson Mandela, que se formou pela Universidade da África do Sul (Unisa), fazendo um curso por correspondência. No Brasil, cresce a importância da EAD em diferentes áreas, com destaque para as instituições públicas. Hoje, por vivermos em um ambiente em que a busca pelo conhecimento é premente e reter talentos é essencial para o bom desempenho da organização, torna-se indispensável promover a educação a qualquer hora e em qualquer lugar. Para Gardênia Abbad, psicóloga e professora da Universidade de Brasilia, faz-se necessária a democratização do acesso à educação, o que seria difícil de se alcançar integralmente no serviço público brasileiro, se feito de forma presencial. Assim, entender qual seria o papel da EAD em ambientes corporativos, bem como os desafios a serem enfrentados, torna-se fundamental para a obtenção de seu objetivo principal: "Incluir a todos em um mundo de aprendizagem contínua, para atender às necessidades das pessoas, à busca por competências", diz a professora. Muitos desses desafios foram discutidos no Seminário Internacional de Educação a Distância, realizado pela ENAP em junho de 2007, que contou com a presença de especialistas franceses, canadenses, espanhóis e brasileiros $^{1}$.

\section{Desafios em educação a distância}

\section{Quem é o estudante de EAD}

Conhecer o público-alvo do curso a ser ofertado é fundamental para minimizar índices de evasão. Para manter-se motivado, o servidor público estudante precisa conciliar atividades do seu cotidiano com trabalho e estudo, o que exige cuidado diferenciado na elaboração dos cursos em EAD. Muitos alunos freqüentam as salas de aula virtuais no período noturno e aos finais de semana; às vezes são mulheres que procuram compatibilizar o horário dedicado ao aprendizado e à atenção à família; ou ainda pessoas de idade mais avançada que, para acompanhar o curso, necessitam de mais tempo para familiarizarem-se com a tecnologia. Por essas razões, na opinião da psicóloga, é importante que o aluno tenha a possibilidade de fazer o seu próprio horário de estudo, sem limitações temporais e sem a obrigatoriedade de presença simultânea às aulas. Em outras 
palavras, diz, "é necessário pensar em estudos assíncronos, em que haja momentos distintos de aprendizagem".

Para Ana Sofía Cardenal Izquierdo, da UOC², "é preciso buscar, cada vez mais, maior personalização e universalização da educação, porém respeitando as especificidades do aluno". desempenho laboral próprio ou de colegas; se o conteúdo do curso é muito extenso, pode-se pensar em oferecê-lo também em mídia impressa, para facilitar a leitura na hora do estudo; ou ainda, se o aluno opta por estudar em uma biblioteca, o curso não pode ser ofertado apenas com ênfase no áudio.

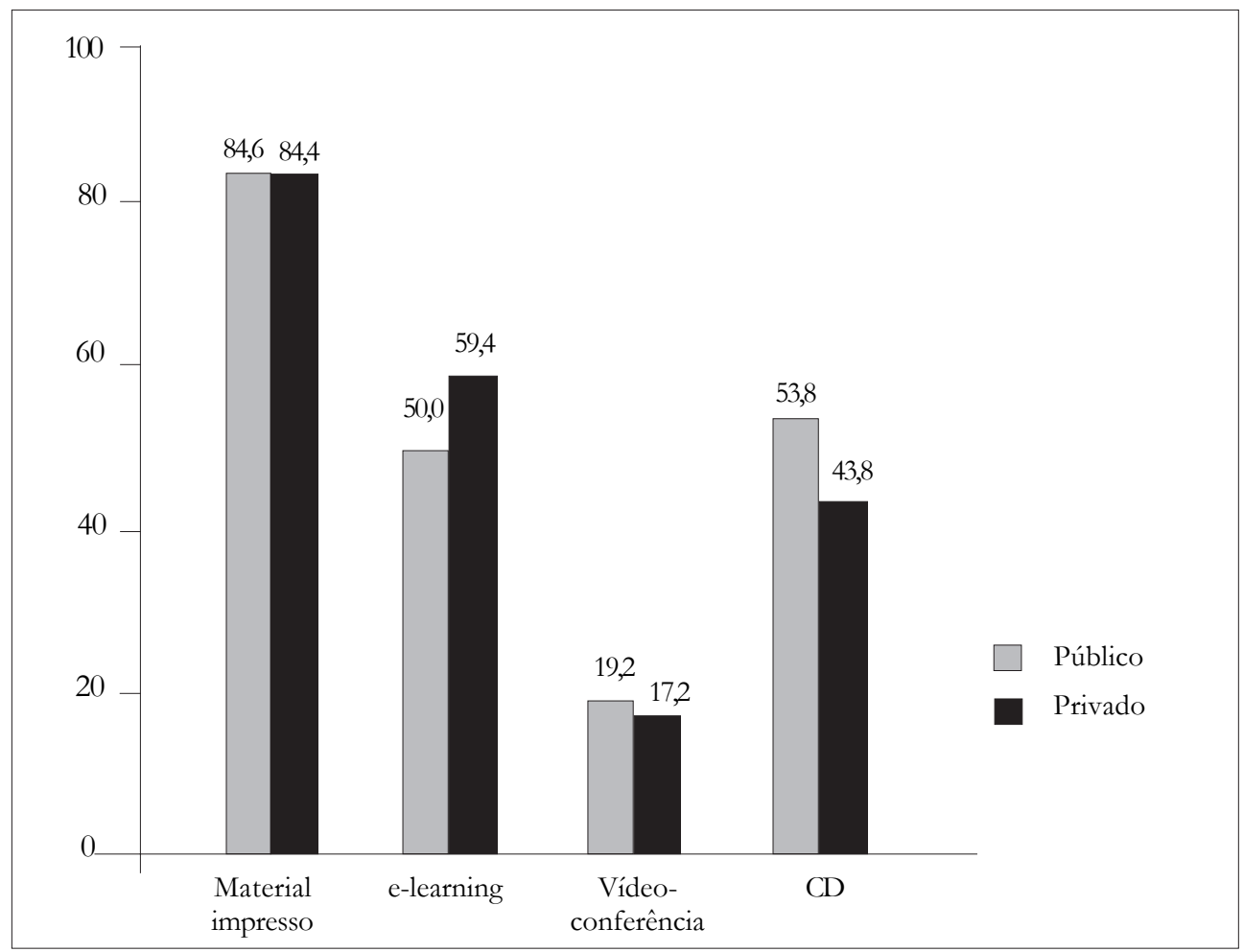

Fonte: Manual brasileiro estatístico de educação aberta e a distância (Abraead), 2007

\section{Gráfico 1: Distribuição das instituições públicas e privadas segundo as mídias utilizadas e sua natureza jurídica (em porcentagem)}

Vale ressaltar que uma análise prévia do perfil dos alunos ajuda na escolha das mídias utilizadas, no tipo de avaliação, na linguagem e na forma de apresentação do conteúdo e no planejamento do tempo de duração do curso. Se o estudante fará as atividades de capacitação propostas no ambiente de trabalho, é necessário que essas sejam planejadas de forma que o tempo de execução não atrapalhe o seu

\section{Como tornar os cursos mais} atraentes e criativos

O diretor do Centro de Formação dos Servidores Públicos da Uned $^{3}$, Eustaquio Martín, chama a atenção para a integração dos recursos tecnológicos com as metodologias utilizadas, bem como para o papel que essa integração exige dos distintos atores envolvidos no processo e como eles poderiam suplantar algumas das 
deficiências observadas no uso dessas novas tecnologias. Para ele, é essencial saber usar as soluções tecnológicas, mas sem perder de vista a proposta pedagógica da instituição. Assim, um projeto pedagógico deve ser pensado considerando a conexão entre tecnologia e metodologia.

Muitos ambientes virtuais de aprendizagem oferecem tecnologias variadas, porém subaproveitadas. "Muitos dos cursos apresentam um hyperlink de navegação que, quando acionado, não possibilita uma livre navegação ao aluno: o hyperlink está conectado à plataforma do curso", explica Abbad. O aluno, então, fica limitado ao ambiente oferecido e impossibilitado de pesquisar em outros sites da Internet.

É incongruente oferecer um curso em que as tecnologias presentes não favorecem o auto-aprendizado, visto que um dos pilares em educação a distância é a autonomia do aluno, que constrói o seu próprio ritmo de aprendizagem e busca novos conhecimentos. Um curso que não possibilita essa "viagem" virtual trabalha de maneira unidirecional e foca apenas a transmissão do conteúdo. Desenvolver habilidades e capacidade de auto-aprendizado é peça-chave para manter o aluno interessado. O servidor público é o estudante que reconhece o valor do conhecimento, a necessidade de constante atualização e acompanhamento de mudanças, necessitando explorar isso por conta própria. Um curso que não oferece o desenvolvimento das competências às quais a EAD se propõe contribui para a evasão do aluno, e não à sua motivação para participação e conclusão do curso.

\section{Os números da ENAP}

Ainda na década de 1980, a Escola adotou a mídia impressa para a oferta de cursos a distância. Em 2004, já com o advento da Internet, foi criada a Coordenação-Geral de Educação a Distância, com o início das atividades de sua Escola Virtual no mesmo ano. Entre os objetivos da EAD na ENAP encontram-se a democratização do acesso ao conhecimento, o autodesenvolvimento do servidor, o desenvolvimento de competências institucionais e a otimização de custos. Os números abaixo representam o desenvolvimento da EAD na Escola ${ }^{4}$.

Total de servidores:

- entre outubro de 2004 e dezembro de 2006: 22.640

- até junho de 2007: 9.307

Distribuição quanto ao gênero:

- feminino: $44,6 \%$

- masculino: $55,4 \%$

Distribuição por idade:

- até 30 anos: $22 \%$

- de 31 a 40 anos: 37\%

- de 41 a 50 anos: 33\%

- mais de 50 anos: $8 \%$
Distribuição por escolaridade:

- Ensino médio: 22,3\%

- Ensino superior: 77,7\%

Distribuição geográfica por região:

- Norte: $11,6 \%$

- Nordeste: $16,9 \%$

- Centro-oeste: $32 \%$

Cursos mais procurados:

- Ética e serviço público: 19\%

- Legislação aplicada à gestão de pessoas: $12 \%$

- Legislação aplicada à logística de suprimentos: $8 \%$

Fonte: Coordenação-Geral de Educação a Distância/ENAP (com adaptações). 


\section{Como avaliar o aluno}

Um dos grandes preconceitos em relação a EAD é a sua suposta falta de qualidade, e um dos fatores que corroboram com essa idéia é a forma de elaboração do sistema avaliativo dos cursos. Ainda apresentada de forma banalizada e com baixo nível de complexidade, a maioria das avaliações deixa de analisar as competências propostas e fixa-se apenas na averiguação da aquisição de conteúdos. "Ensinar procedimentos não é o mesmo que ensinar a resolver problemas", ressalta Luis Felipe Paradela, Assessor para a Tecnologia de Informação e Conhecimento do Inap ${ }^{5}$. E isso também deve ser considerado em termos de avaliação.

As avaliações aparecem, freqüentemente, em forma objetiva, com questões de múltipla escolha, falso ou verdadeiro ou preenchimento de lacunas e, por isso, são percebidas como de retenção e aplicação de conteúdos. Há pesquisas que mostram a insatisfação de alunos, que chegam a questionar se os testes condizem com as competências propostas originalmente pelos cursos.

Quando o ideal perseguido atualmente é um modelo de gestão de pessoas baseado em suas competências, considerar apenas o conhecimento e não incluir as habilidades e atitudes a serem desenvolvidas pelo aluno, no caso, o servidor público, não é suficiente. Competências como responsabilidade, autonomia, disciplina e assiduidade são desenvolvidas ao longo do estudo em EAD e precisam ser consideradas no momento da avaliação.

Para torna-se mais eficaz, a avaliação deve ocorrer em todos os momentos da aprendizagem, e não apenas na conclusão de um módulo ou de um curso. Isso aumenta a importância da figura do tutor, responsável pelo acompanhamento do estudo do aluno e do seu desempenho ao longo do curso.

O papel do tutor baseia-se em três funções: a do professor, do educador e do tutor em sentido estrito. $\mathrm{O}$ primeiro faz o acompanhamento pedagógico do estudante e do aprendizado; o segundo tem por objetivo ajudar o aluno a desenvolver valores, como a autonomia de aprendizagem; o terceiro foca em construir vínculos emotivos com o aluno, trabalhando com a interatividade e a afetividade para minimizar a distância transacional. O bom tutor tem como características fundamentais o domínio das tecnologias utilizadas, o conhecimento do conteúdo ofertado e, principalmente, a capacidade de ser empático, de colocar-se no lugar do aluno e entender como está sendo o seu aprendizado, oferecendo-lhe, sempre, o feedback necessário para que o estudante não se sinta abandonado e, conseqüentemente, desestimulado.

\section{Novos caminhos em educação a distância}

Investir em um perfil de servidor público capaz de refletir criticamente sobre a realidade organizacional, construí-la e modificá-la parece ser o caminho das organizações modernas, que vêm encarando os desafios apresentados de forma inovadora ${ }^{6}$.

Hoje, percebe-se que para acabar com os preconceitos em torno da EAD em instituições públicas é necessário sensibilizar direção e chefias imediatas de forma a estimular a EAD e as modalidades mistas de aprendizagem nas organizações ${ }^{7}$.

Nos programas desenvolvidos pelo $\mathrm{Ceddet}^{8}$, por exemplo, o público participante não se inscreve diretamente. "A solicitação de inscrição é feita pela instituição e o superior hierárquico tem que 
propor o nome dos participantes", diz Ricardo Cospedal, diretor-adjunto do Centro. Faz-se, assim, um trabalho de sensibilização dos superiores, no sentido de colaborar com a redução da jornada de trabalho e permitir a alocação de equipes da própria instituição para a coordenação dos cursos. "Nosso contato é tanto com o participante, como com a chefia. Todos os informes, todas as avaliações e relações que mantemos com os alunos são estabelecidos, ao mesmo tempo, com seus chefes. Nosso objetivo é institucional e não pessoal", completa Cospedal.

"Na Espanha, pelo novo Estatuto Básico da Função Pública, o crescimento profissional do funcionário deve ser feito mediante conhecimento e cursos realizados, ou seja, deve-se estabelecer um vínculo entre a formação e a promoção profissional do servidor", diz o assessor do INAP. Assim, a EAD aparece como uma ferramenta-chave ao desenvolvimento no serviço público.

No caso do Brasil, esse talvez seja o maior desafio para o sucesso da implementação da EAD em instituições públicas: a conscientização da importância da democratização de oportunidades para a formação. Para o diretor-adjunto do Ceddet, "o acesso à tecnologia é simples, os programas são simples do ponto de vista tecnológico. A diferença é a qualidade, é convencer o funcionário de que se trata de um investimento e que vale a pena empregar duas ou três horas de sua jornada diária para a sua formação".

\section{Notas}

* Esta reportagem foi elaborada com base no Seminário Internacional de Educação a Distância, ocorrido na ENAP, bem como nas entrevistas concedidas pelos participantes e nas palestras apresentadas. Agradecemos aos palestrantes e participantes do evento, que nos ofereceram momentos de grande aprendizado durante as discussões:

- Centro de Educação à Distância para o Desenvolvimento Econômico e Tecnológico (Ceddet)

Ricardo Cospedal García, Diretor-Adjunto do Ceddet/Espanha

- Escola Canadense do Serviço Público (CSPS)

Professora Barbara Lukaszewicz, Diretora Geral do Centro de Blended Learning da CSPS/ Canadá

- Instituto de Gestão Pública e Desenvolvimento Econômico (IGPDE)

Professora Nathalie Tournyol du Clos, Diretora-Adjunta do IGPDE/França

- Instituto Nacional de Administração Pública (Inap)

Luis Felipe Paradela, Assessor para Tecnologia de Informação e Conhecimento do Inap/ Espanha

- Universidade Aberta da Catalunha (UOC)

Ana Sofia Cardenal Izquierdo, Diretora do Programa de Ciências Políticas da UOC/Espanha - Universidade de Brasília (UnB)

Gardênia Abbad, Psicóloga e Professora do Instituto de Psicologia da UnB/Brasil

- Universidade Nacional de Educação à Distância (Uned)

Eustaquio Martín, Diretor do Centro de Formação de Servidores Públicos da Uned/Espanha

- Escola Nacional de Administração Pública

Margareth Baroni, Diretora de Desenvolvimento Gerencial, ENAP/Brasil 
- Escola Nacional de Administração Pública

Tarcilena Polisseni Cotta Nascimento, Coordenadora-Geral de Educação a Distância, ENAP/ Brasília

${ }^{1}$ Entre as instituições internacionais presentes no evento estavam: Centro de Educação a Distância para o Desenvolvimento Econômico e Tecnológico (Ceddet), da Espanha; Escola Canadense de Serviço Público (CSPS), do Canadá; Instituto de Administração Pública e Desenvolvimento Econômico (IGPDE), da França; Instituto Nacional de Administração Pública (INAP), da Espanha; Universidade Aberta da Catalúnia (UOC), da Espanha; e Universidade Nacional de Educação a Distância (Uned), da Espanha.

${ }^{2}$ A Universidade Aberta da Catalunha (UOC) é uma universidade que tem como missão facilitar a formação de pessoas ao longo da vida. O propósito da Universidade é conseguir que cada pessoa possa satisfazer suas necessidades de aprendizagem aproveitando ao máximo o seu esforço. Com essa finalidade, a Universidade utiliza os recursos de TI para superar as barreiras de tempo e espaço e um desenho educacional baseado na personalização e acompanhamento integral do estudante. Para mais informações: <www.uoc.edu>.

${ }^{3}$ Universidade Nacional de Educação a Distância (Uned). Fundada em 1972, é hoje a maior universidade da Espanha, com mais de 160 mil alunos. Tem como um de seus objetivos garantir a igualdade de oportunidades, possibilitando o acesso ao ensino superior de pessoas que, por alguma dificuldade, ficariam impossibilitadas de estudar. Para mais informações: <www.uned.es>.

${ }^{4}$ Os números referem-se ao período de outubro de 2004 a dezembro de 2006 e consideram o número de servidores públicos capacitados concluintes.

${ }^{5}$ O Instituto Nacional de Administração Pública (Inap) atua como o centro da administração pública do Estado, responsável pela seleção e formação de seus dirigentes e servidores públicos. É um órgão autônomo ligado ao Ministério da Administração Pública, por meio da Secretaria Geral para a Administração Pública da Espanha. Para mais informações: <www.inap.map.es>.

${ }^{6}$ Para conhecimento do relato de experiências ver: Educação a distância em organizações públicas. Mesa-redonda de pesquisa e ação. Brasília: ENAP, 2006.

7 A Escola Canadense do Serviço Público (CSPS) possui um campus on-line denominado 'Campusdirect', que incorpora técnicas de blended learning, focadas na aprendizagem assistida por tecnologias adequadas. As novas técnicas desenvolvidas pela CSPS incluem os seguintes passos: uso de software colaborativo para intercâmbio de documentos, programas de áudio baixados em computadores ou aparelhos portáteis (podcasts), comunidades virtuais de prática e salas de aula virtuais. Para mais informações: <www.csps-efpd.gc.ca>.

${ }^{8}$ O Centro de Educação a Distância para o Desenvolvimento Econômico (Ceddet) é uma fundação ligada ao Ministério da Economia e Fazenda e associada à Rede Global de Aprendizagem para o Desenvolvimento e ao PNUD. Tem como objetivo compartilhar com outros países, principalmente da América Latina, experiências, competências e habilidades acumuladas na administração pública, mediante a utilização de novas tecnologias e com a finalidade de contribuir para o fortalecimento institucional e criar um clima favorável para o investimento na região, bem como uma rede internacional de especialistas, principalmente, ibero-americanos. 